\title{
An investigation into the heat release and emissions from counterflow diffusion flames of methane/dimethyl ether/hydrogen blends in air
}

\author{
Atmadeep Bhattacharya, Saptarshi Basu \\ Department of Mechanical Engineering, Indian Institute of Science, Bangalore - 560012, India
}

Supplementary Figures*:

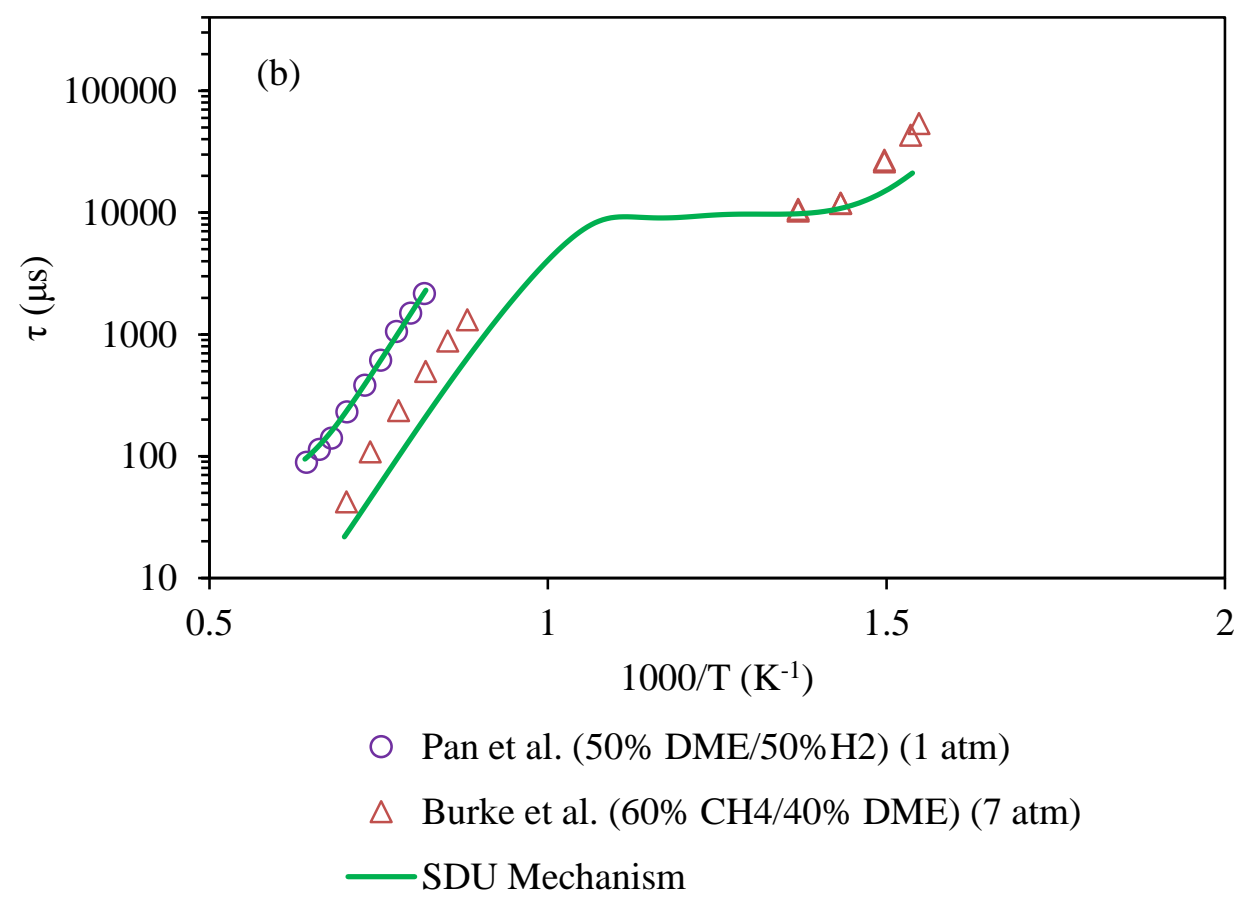

Fig. S1. Assessment of performance of the SDU mechanism in predicting the ignition delay time of 1:1 $\mathrm{DME} / \mathrm{H}_{2}$ and 3:2 $\mathrm{CH}_{4} / \mathrm{DME}$ blends for different temperatures at stoichiometric condition. The experimental data are taken from $[63,64]$.

\footnotetext{
* All reference numbers are according to the main manuscript
} 


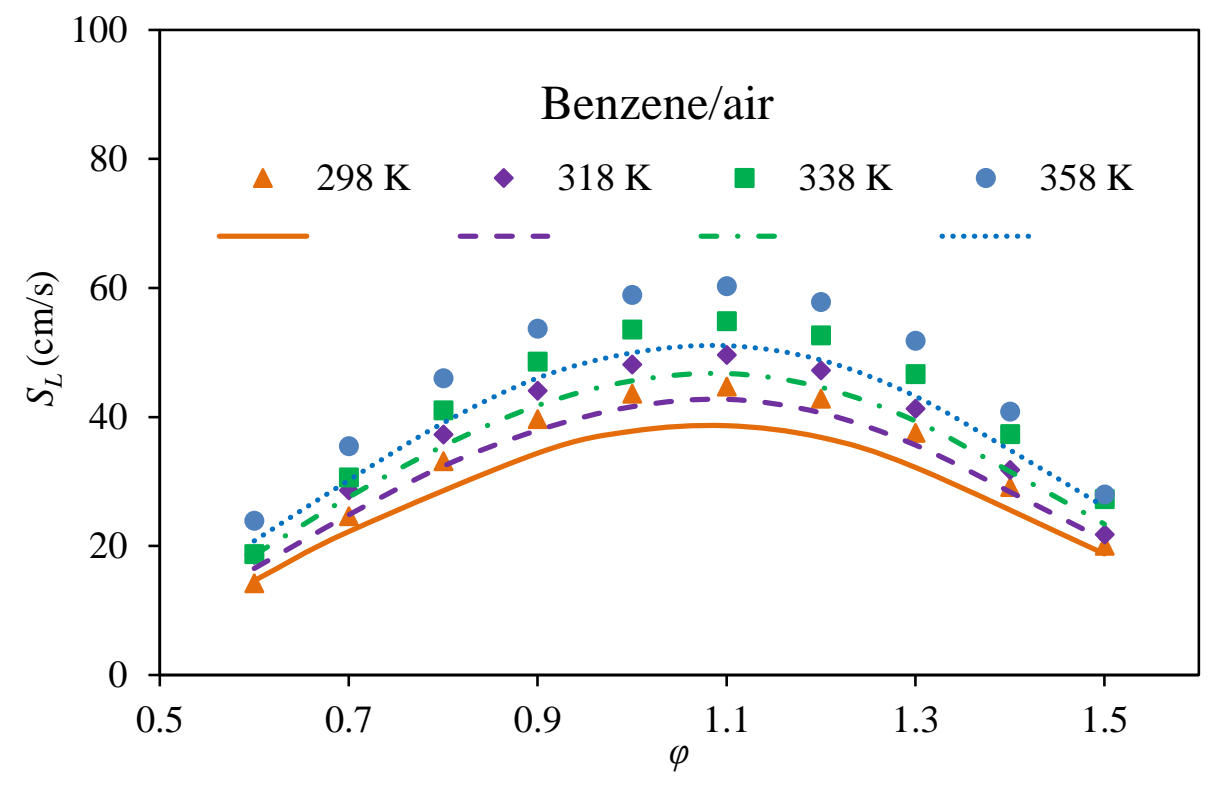

Fig. S2. Assessment of performance of the DUI mechanism in predicting the laminar burning velocity of $\mathrm{C}_{6} \mathrm{H}_{6}$-air mixture at atmospheric pressure and different unburnt gas temperatures. The experimental data are taken from [70]. 


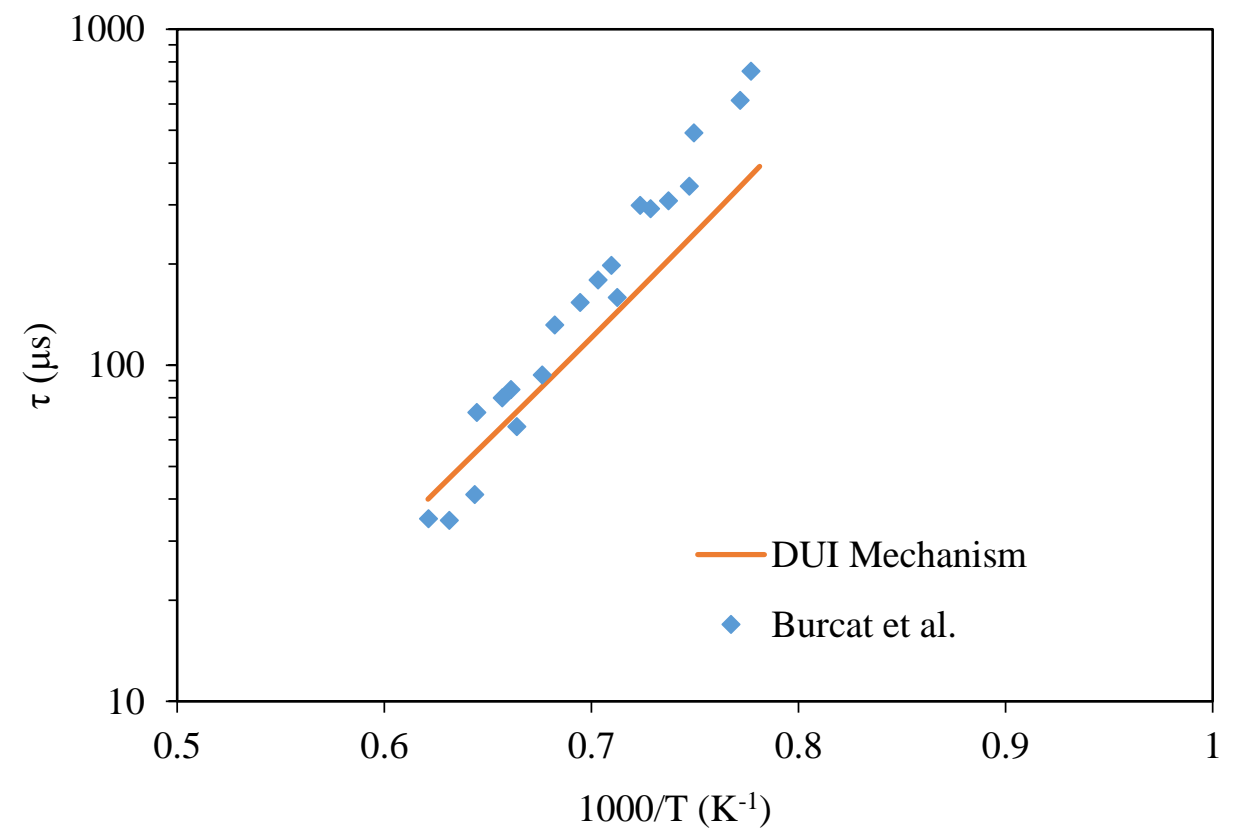

Fig S3. Assessment of performance of the DUI mechanism in predicting the ignition delay time of stoichiometric $\mathrm{C}_{6} \mathrm{H}_{6} / \mathrm{O}_{2} / \mathrm{Ar}$ mixture at 2.5 atm pressure and different temperatures. The experimental data are taken from [71]. 


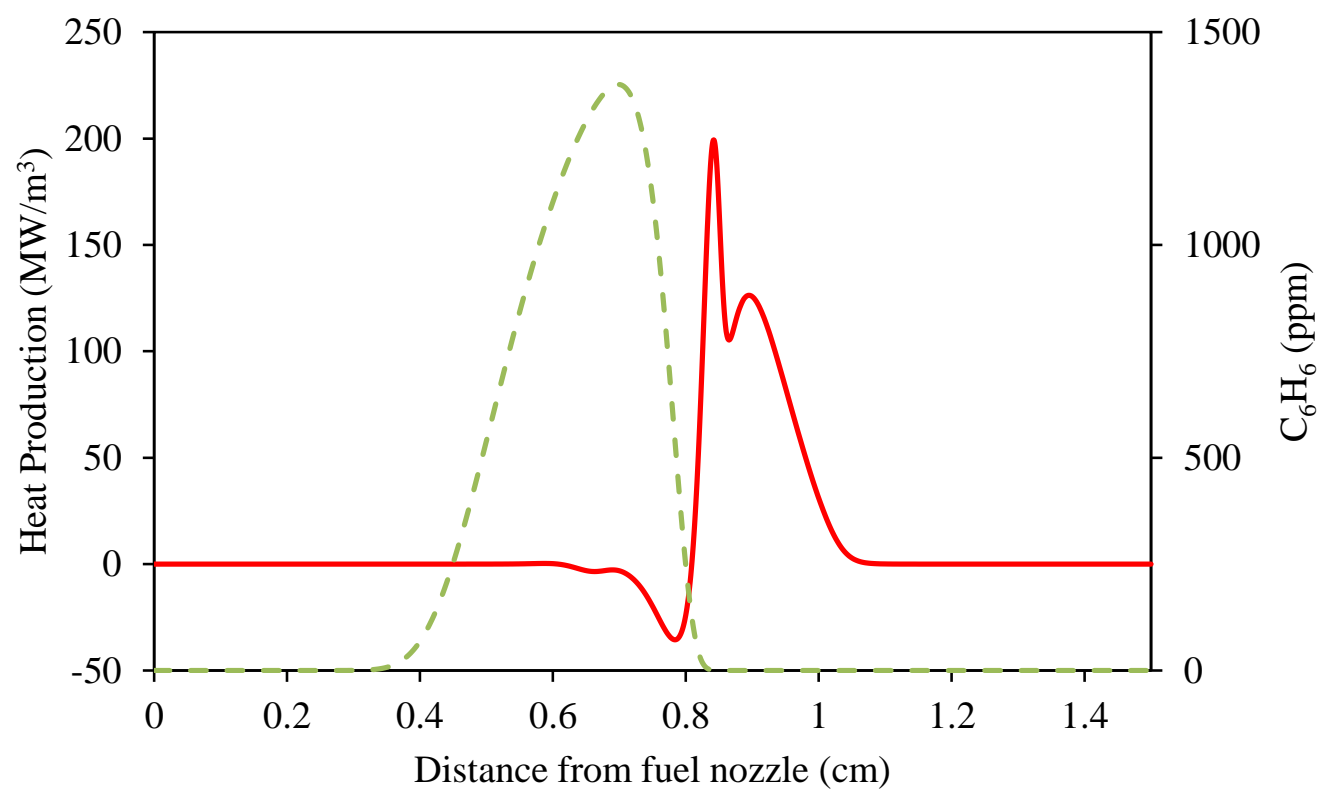

Fig. S4. Variation of $\mathrm{C}_{6} \mathrm{H}_{6}$ mole fraction (ppm) and heat production from gas phase reactions for counterflow diffusion flame of $90 \% \mathrm{CH} 4 / 10 \%$ DME blend in air across the computational domain. Air and fuel stream temperatures are $300 \mathrm{~K}$ and global strain rate is $34 \mathrm{~s}^{-1}$. 


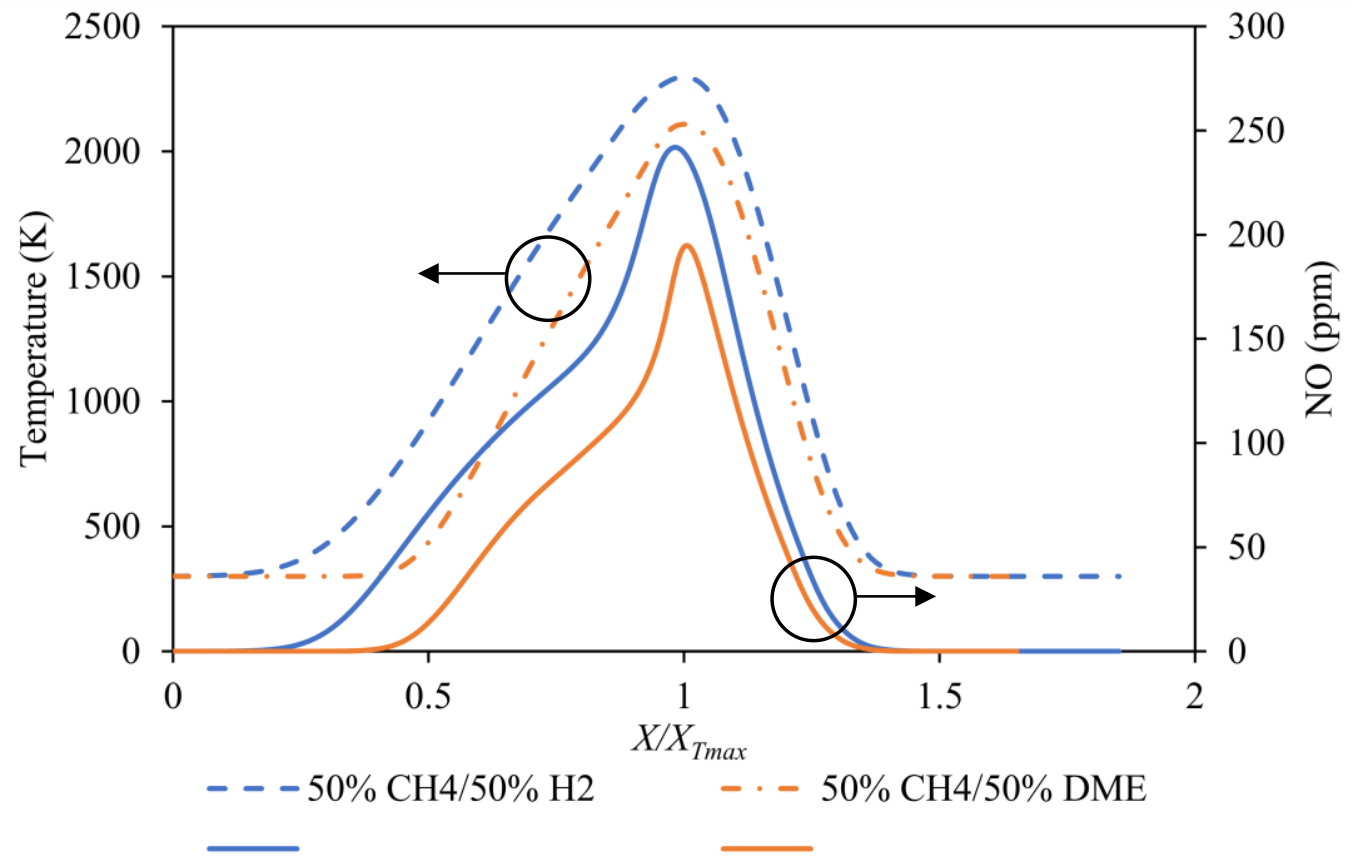

Fig. S5. Variation of temperature and NO mole fraction (ppm) for counterflow diffusion flames of 50\% $\mathrm{CH} 4 / 50 \% \mathrm{H}_{2}$ and $50 \% \mathrm{CH} 4 / 50 \%$ DME blends in air across the computational domain. Air and fuel stream temperatures are $300 \mathrm{~K}$ and global strain rate is $34 \mathrm{~s}^{-1}$. 


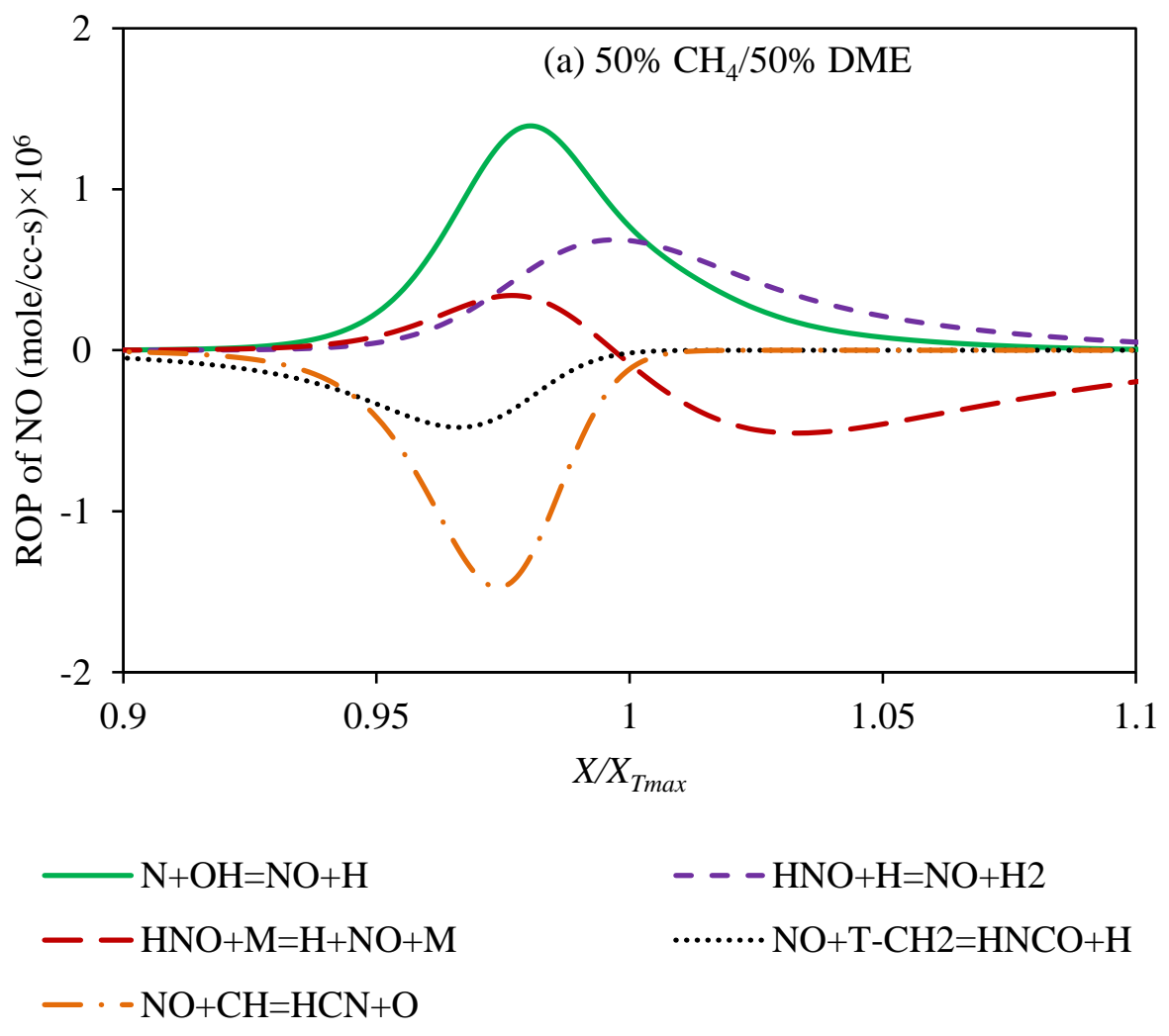



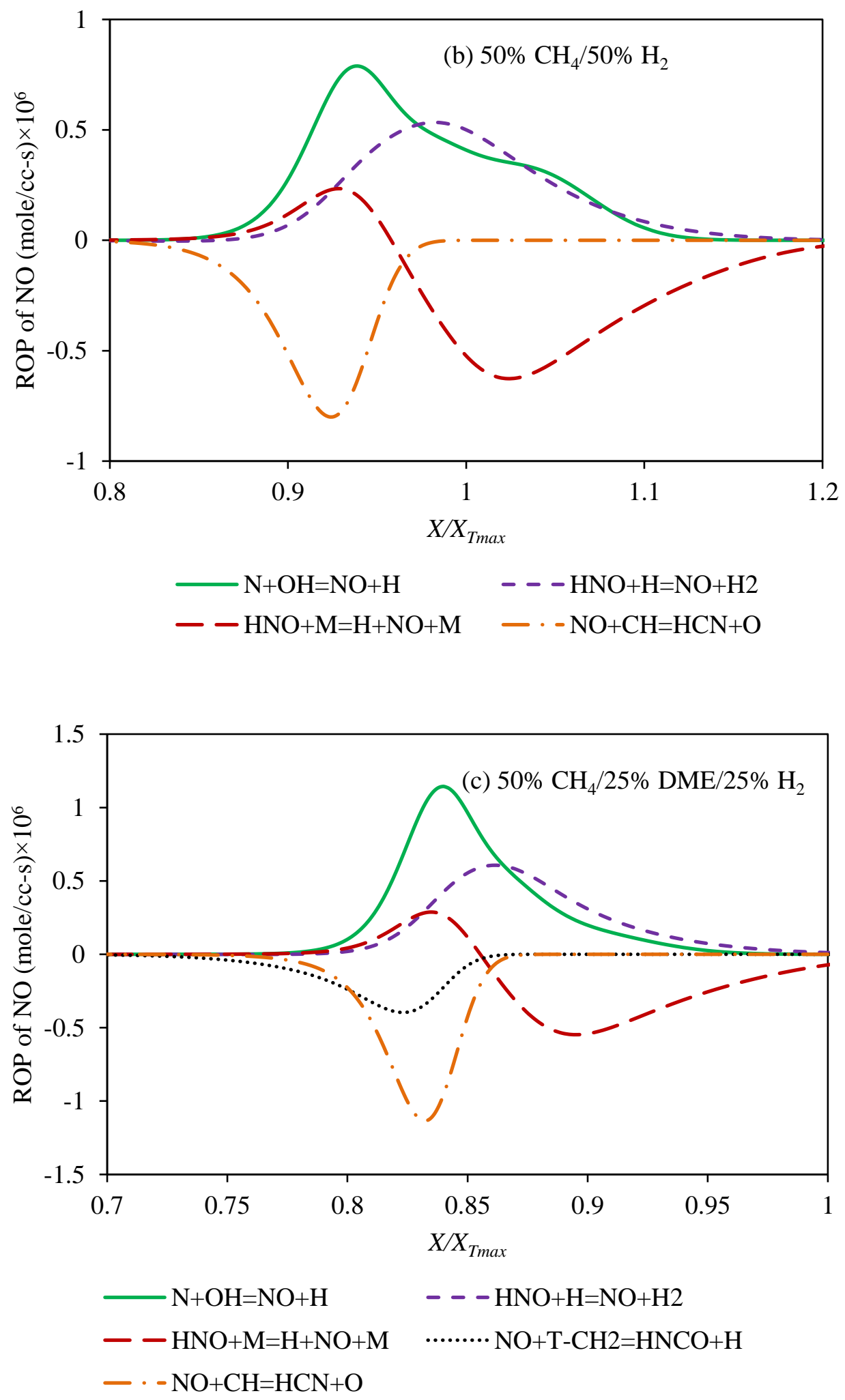

Fig. S6. Main contributing reactions towards production of NO for (a) $50 \% \mathrm{CH}_{4} / 50 \%$ DME (b) $50 \%$ $\mathrm{CH}_{4} / 50 \% \mathrm{H}_{2}$ and (c) $50 \% \mathrm{CH}_{4} / 25 \% \mathrm{DME} / 25 \% \mathrm{H}_{2}$ blend. 